\title{
Erratum to: Silencing of a second dimethylallyltryptophan synthase of Penicillium roqueforti reveals a novel clavine alkaloid gene cluster
}

\author{
Ángeles Fernández-Bodega ${ }^{1} \cdot$ Rubén Álvarez-Álvarez ${ }^{2}$ Paloma Liras ${ }^{2}$. \\ Juan F. Martín ${ }^{2}$
}

Published online: 12 September 2017

(C) Springer-Verlag GmbH Germany 2017

Erratum to: Appl Microbiol Biotechnol (2017) 101:6111-6121

https://doi.org/10.1007/s00253-017-8366-6

Figure $5 \mathrm{~A}$ in the article has an error in the structures of isofumigaclavines $\mathrm{A}$ and $\mathrm{B}$.

A corrected Fig. 5A is included below:

The online version of the original article can be found at https://doi.org/ 10.1007/s00253-017-8366-6

Juan F. Martín

jf.martin@unileon.es

1 Institute of Biotechnology of León (INBIOTEC), Av. Real 1,

24006 Leon, Spain

2 Microbiology Section, Department of Molecular Biology, University

of León, 24071 Leon, Spain 
<smiles>CC(C)=CCOc1ccccc1</smiles>

Tryptophan + DMA-PP

ifgA

isofumigaclavine A

$$
\text { ifgl }
$$<smiles>CC(=O)O[C@H]1[C@@H](C)CN(C)[C@H]2Cc3c[nH]c4cccc(c34)[C@H]12</smiles><smiles>C/C=C\Cc1cccc2[nH]cc(CC(N)(N)C(=O)O)c12</smiles>

Dimethylallyltryptophan

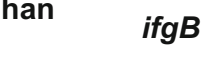

isofumigaclavine $B$<smiles>C[C@@H]1CN(C)[C@H]2Cc3c[nH]c4cccc(c34)[C@H]2[C@H]1O</smiles><smiles>CN[C@@H](Cc1c[nH]c2cccc(CC=C(C)O)c12)C(=O)O</smiles>

$\mathrm{N}$-methyl-dimethylallyl tryptophan

gH

festuclavine<smiles>C[C@H]1CN(C)[C@]2(C)Cc3c[nH]c4cccc(c34)[C@@H]2[C@@H]1C</smiles>

$\mathrm{OH}$<smiles>CC/C(C)=C/C1c2cccc3[nH]cc(c23)C[C@H]1NC</smiles>
chanoclavine I

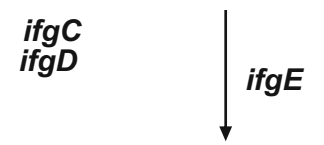

$$
\text { ifg } F \text { aldehyde }
$$

ifgG<smiles>CNC1Cc2c[nH]c3cccc(c23)C1/C=C(\C)C=O</smiles> 